\title{
Confrontaciones entre la historia y escuela: EI Puquina en el Sur Andino
}

Confrontations between history and school: The Puquina in the Andean south

Mario Zapata Delgado

Escuela de Graduados Pontificia Universidad Católica, Lima Perú.

\section{INFORMACIÓN}

\section{Historia del Artículo}

Recepción: 07/10/2019

Revisión: 05/11/2019

Aceptación: 09/12/2019

\section{Palabras Clave}

Puquina, historiografía, origen primordial, coexistencia étnica, percepción y representación.

\section{Key Words \\ El Puquina, historiography, primordial origin, ethnic coexistence,} perception and representation

\section{DOI}

https://doi.org/10.35286/veritas. v21i1.259

\begin{abstract}
RESUMEN
Desde que se ha dado con la existencia del puquina en la vertiente occidental ha sido punto de concentración de estudios lingüísticos, antropológicos e históricos, los cuales ha pretendido demostrar su existencia. Va desde la cuenca del Chili (Arequipa) hasta Atacama en algunos autores y otros hasta el Sama en Tacna, lo cierto es que se ha creado una corriente historiográfica basada en "el ídolo de los orígenes" la cual presume sobre la actuación puquina en esta región, lo cierto es que hubo enclaves, puquinas, además de aymaras, quechuas, coli y una forma de atacameño en la zona, entonces se busca reformular el conocimiento de los asentamientos étnicos y culturales su intervención y protagonismo en Arequipa. A pesar de cobijar esta herencia, la escuela se mantiene al margen de la importancia de la presencia puquina; ni el diseño curricular, menos la contextualización, diversificación, concreción y toda la prolífica gama de "cion" que existen como etiquetas del MINEDU, han servido para fortalecer saberes que permitan una nueva mirada de la historia de Arequipa y sobre todo recrear una memoria e identidad, como producto de la diversidad. Más bien se aprecia una reinvención de los puquina en términos de herencia cultural; desde la academia, gobiernos locales y prácticas ciudadanas.
\end{abstract}

\begin{abstract}
Since the existence of culture, language, and western Puquina ethnicity has been a focal point of linguistic, anthropological and historical studies, which has tried to demonstrate the existence of the Puquina in this area that goes from the basin of the Chili (Arequipa) to Atacama in some authors and others to the Sama in Tacna, the truth is that a historiographic current has been created based on "the idol of the origins" which presumes about the action puquina in this region, the truth is That what existed were enclaves, puquinas like Aymaras and Quechuas besides coli and a form of atacameño in the zone, then it is sought to reformulate its intervention and protagonism in the zone. We also note that a reinvention of the puquina is taking place in terms of cultural heritage, from the local government academia and citizen practices.
\end{abstract}

\section{INTRODUCCIÓN}

Se propone un acercamiento a las raíces históricas de la formación cultural en el surandino en general, y Arequipa en particular, se trata de mostrar un panorama sobre historia que se acuña en el pasado poco estudiado como es el Puquina; de una parte se considera que los ancestros prehispánicos que se asentaron en la cuenca del Chili fueron quechuas y aymaras, provenientes de la zona Collagua; altiplánica; Cusco y Apurímac, siendo nimio la presencia puquina, lo cual exige estudios más profundos para desentrañar su importancia.

El otro entuerto se refiere a que existe una confrontación vieja entre la historia que se enseña y la historia que se investiga, existe una brecha enorme en el currículo oficial del Perú, el docente y la gestión del conocimiento.

De otro lado la preeminencia en educación superior pedagógica de los métodos sobre los saberes, hacen tabula rasa de contenidos necesarios para fortalecer elemento identitario y un reconocimiento de nuestra diversidad, no se trata de los orígenes como búsqueda inicial de donde provenimos, sino más bien de recordar que nuestra diversidad que se ha oficializado, pende de lo que nosotros somos capaces de utilizar como memoria, ya que es ella la que recrea y se redefine constantemente.

Justamente este estudio intenta un acercamiento a esas viejas y nuevas connotaciones entre la historia y la escuela.

Y sobre el particular, hemos tomado como ejemplo un análisis historiográfico de la presencia puquina en Arequipa que lamentablemente esta soslayado en el currículo pero lo más peligroso es el desconocimiento de los maestros de reconocerlo como parte de la memoria e internalizarlo como identidad.

Las fuentes utilizadas son primarias manuscritas e impresas; en esa medida hubo revisión de los archivos de Arequipa; las impresas, fuentes publicadas; además de fuentes secundarias para abordar en historiografía que ha realizado los estudios sobre la cultura puquina.

Finalmente se considera pertinente la apreciación valorativa de los puquinas y su impronta en Arequipa, la cual no tiene este estudio otra significación que difundir aquello que se conoce a medias o se desconoce en nuestras escuelas y nuestros docentes de Ciencias Sociales. 


\section{Puquinas y los estudios históricos y lingüísticos}
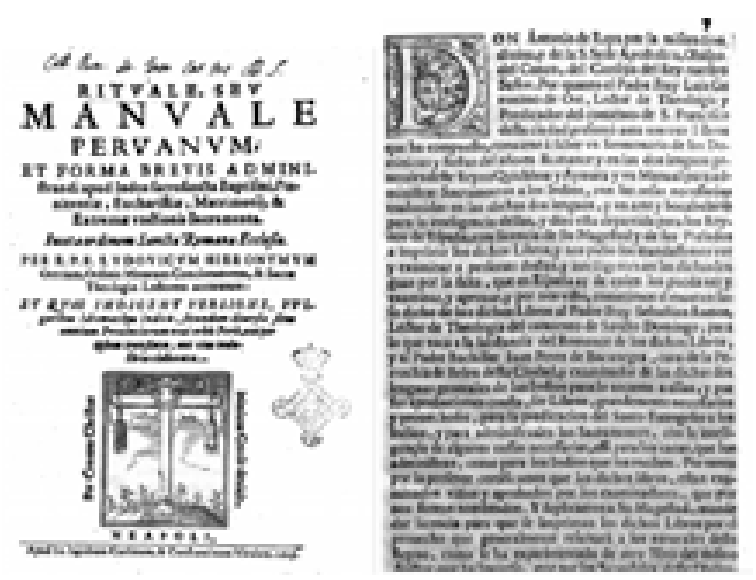

Ilustración 1: Catecismo en puquina elaborado por Gerónimo de Oré

Antes de ingresar al puquina como cultura, grupo étnico y lengua en la Chimba y Tiabaya, es necesario hacer las siguientes disgregaciones sobre sus orígenes expansión y naturaleza en el espacio prehispánico y por ende en la Chimba. Posiblemente, según Arkush, el Periodo Altiplano ${ }^{1}$ , hubo migraciones entre regiones. Tanto Torero (1987) como Cerrón-Palomino (2000) infieren desplazamientos masivos del habla aymara sobre la vertiente occidental originando una agonía del Puquina, la cual se precisa a partir de documentos de qarchivo en Arequipa sue xtinción en el siglo XIX . proponen que el periodo Altiplano como un tiempo de inestable debido a los enfrentamientos puquinascollas(Arkush, 2012).

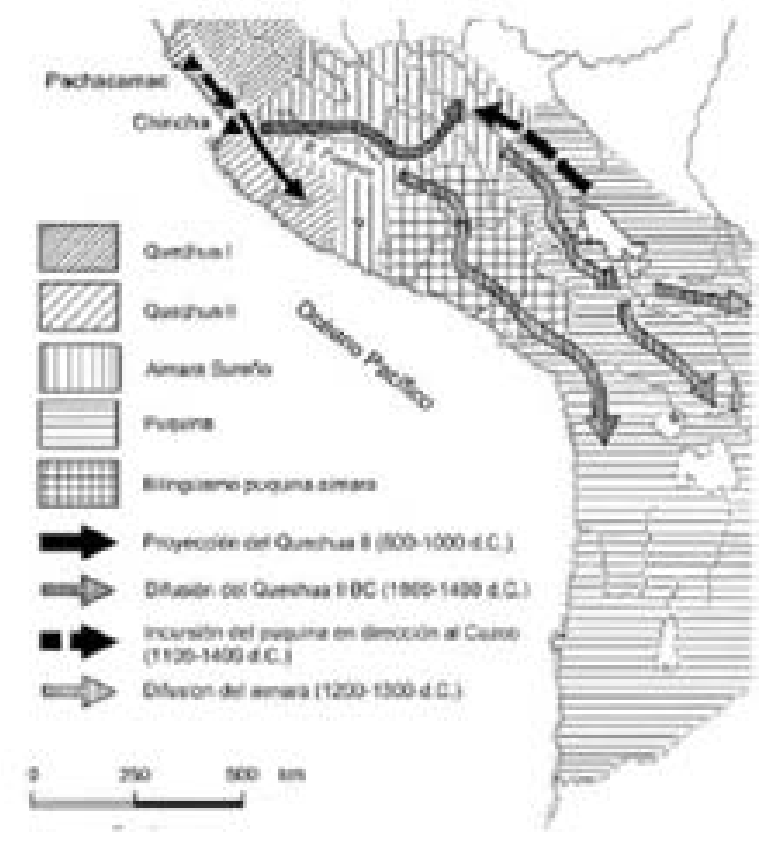

Los Puquinas, tuvieron en el Collasuyu una presencia que púede ser entendida como colonizadores y colonizados en el contexto Tiahuanaco (Bouysse-Cassagne, 2010, pág. 283). El panandino Inca obligó a los urus a expresarse en aymara ya que esta lengua se universalizo debido ala demanda de comerscio política y cultura (Bouysse-Cassagne 1987: 117). Lo que coadyuvo a ser una lengua segundona ya que todas los intercambios comerciales y de focalización de vida social se inició con el aymara, quedando rezagado esta le lengua, pero hasta el tercer concilio de Lima donde se toma nota para la evangelización en esta lengua generando como general, pero esto es muy precario ya que mucho de lo que hicieron los españoles fue una muestra de desconocimiento y no propiamente la generalización de esta lengua,. Ya que la historia nos dice que estaba en franca decadencia, de ello se deduce que son poquísimas la excepciones en su traducción como son los de Barzana, cuyo tenor determinó el catecismo de Oré los que aprendieron esta lengua y que estuvieron en condiciones de evangelizar con conocimientos acerca de ella. Comprender como es que habiéndose implementado el Aymara inicialmente y luego el Quechua se reconocen muchos topónimos puquina en la vertiente occidental; para ello albergamos algunas conjeturas por ejemplo el puquina es anterior a estas dos lenguas y existe a partir de los estudios realizados que los Tiahuanaco eran puquina hablantes y en su diversas oleadas hacia la vertiente occidental y Omasuyo ha quedado pruebas irrefutables sobre todo en Bolivia de la lengua y de la cultura Puquina estudiados por Bouysse Cassagne, Nathan Watchel, Tierry Saignes por citar para Bolivia; y en el Perú son soportes en esta comprensión los estudios de Bernedo Málaga, Galdós Rodríguez, Alfredo Torero, Cerrón Palomino solo por mencionar algunos más destacados. Por lo tanto, existía un problema real en torno de este idioma. Sin embargo, el diccionario aimara de Bertonio caracterizó a los puquina y a los uru con nombres y, a veces, con apodos diferentes, lo que demuestra que los aimaras no confundían a los dos grupos (Bouysse-Cassagne, 2010). Bertonio señaló que los aimara se referían a los primeros como «kiuchacatati o sea como hígados grandes», mientras que a los uru los consideraban «como una nación de indios despreciados entre todos que de ordinario son pescadores y de menos entendimiento» y que nombraban «uru» a un individuo «andrajoso, o çafio, sayagués y rustico» (Bertonio 1984 [1612]: 380).

Ilustración 2: Distribución y procesos de las lenguas en el Perú prehispánico

\footnotetext{
${ }^{1}$ Según Elizabeth Arkush, el período Altiplano o Intermedio Tardío (1000-1450 d.C. aprox.) es reconocido en la cuenca de Titicaca por el desarrollo de numerosos grupos étnicos alrededor del lago: los lupacas, los collas, los pacajes, etc., los mismos que más tarde figurarán en las crónicas de la conquista Inca y en otros documentos administrativos de la Colonia Temprana estos grupos altiplánicos son descritos como violentos asumiendo un liderazgo dual. Estos grupos fueron sociedades agropastoriles, con fuerte énfasis en la ganadería según se menciona. Lo interdsante de esta propuesta es encontrar que muchos de estas oleadas se asentaron en la zona de cuenca como Carabaya, Larecaja y al oeste en Moquegua, vínculos basados en superposición de espacios interzonales.
} 


\section{Puquinas en Arequipa}

\section{Estudios sobre el puquina en la región}

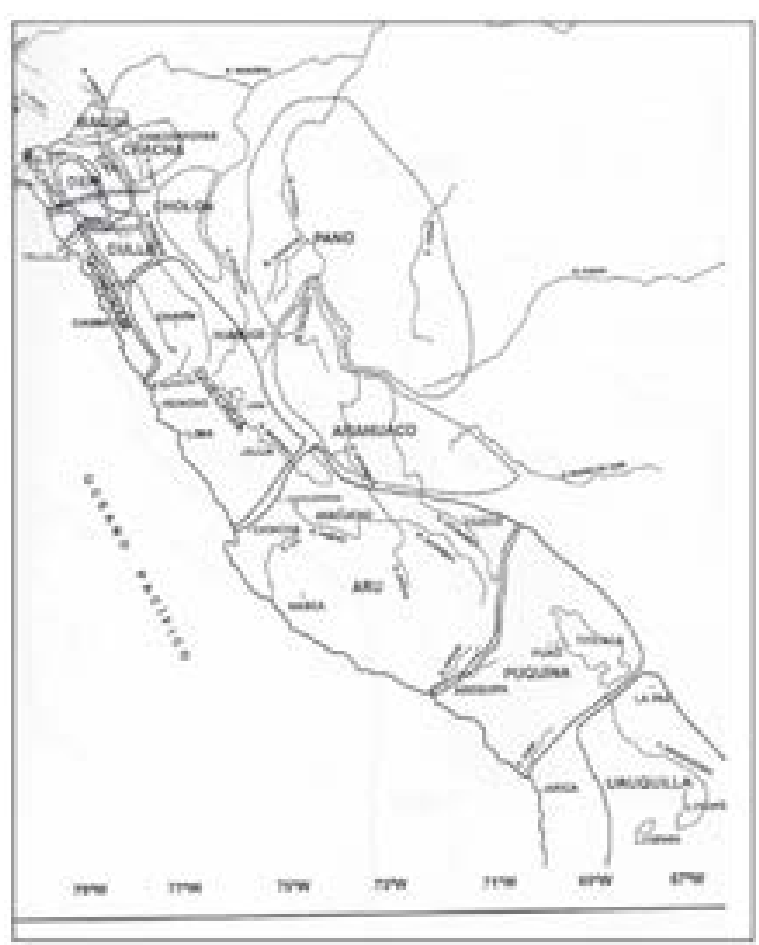

Ilustración 3: Mapa de distribución lingüística propuesta por Alfredo Torero (2002)

Alfredo Torero afirma que para el siglo VI D.C el Puquina era hablado en Arequipa, zona circunlacustre y Cusco. Para el siglo VII existe una fuerte difusión del Aymara desde Wari la cual conlleva a un permanente contacto con el puquina en la zona del Misti y finalmente la ascensión del quechua como lengua de mayor prestigio; la mirada que se procura es de un espacio con diversos grupos étnicos y la convivencia con lenguas diferentes, seria prematura suponer para Arequipa que se dio el establecimiento de una primera lengua y así sucesivamente respecto de las demás; más bien como coexistencias de culturas y lenguas diferentes también es importante asumir que el puquina estaba en decrecimiento respecto de las otras dos.

La fuente etnohistorica es rica para establecer como se llega con todo este abigarramiento lingüístico a la colonia para ello me permito aclarar que para el Kuntisuyu y Colesuyo, la evangelización en esta lengua no fue muy profunda ya que se implementó el quechua y el aymara debido que estas estaban en su apogeo y era la mayoría indígena quienes hablaban en estas lenguas, por lo que para el gobierno español fue conveniente organizar el virreinato e implementar las instituciones como las reducciones, las encomiendas, el pago tributos, lo cual conllevo a una marginalización del Puquina. En 1599, el arzobispo del Cuzco, Don Antonio de La Raya, manifestó su inclinación para que los sacerdotes fueran implementados en la jurisdicción de Arequipa debieran saber el puquina ya que las doctrinas de Zaruma, Hayapaya y Locumba eran hablantes de esta lengua (Créqui Monfort y Rivet 1925-1927: tomo 17, 223) evidenciándose en las constituciones del primer sínodo del obispo de Arequipa ordenaban a "los curas de los pueblos de Arrumas (Carumas), Ilabaya y Locumba que son los que mejor conocen la lengua traduzcan en esta lengua un catecismo y diversas oraciones". Es decir los escritos de evangelización para esta época no habían sido traducidos al puquina, por lo tanto se infiere que era muy poco lo que podía hacer, pero se demuestra la preocupación de los españoles de lograr una uniformidad en este proceso eclesiástico que también tiene la forma económica de exacción (Barriga 1952: 142).

Según la Visita de Álvarez y Jiménez (1792), se consideraba como necesaria en Arequipa «la abolición de la lengua indica [...] no siendo fácil en muchos pueblos de los partidos de Condesuyo, Caylloma, Tarapaca y Arequipa que hablan la quichua, en el de Moquegua la Coli y Aymara, en el de Arica la Aymara sola y en el de Camaná que es corto el número de indios que tiene aunque hablan la quichua, cortan el castellano por estar sus poblaciones inmediatas a la Costa» (Barriga, 1941, pág. 75). Barzana menciona el puquina en el «Altiplano, en Arica, en Arequipa y en la Costa de la Mar» y señaló que «eran en número entre 40 o 50» (BouysseCassagne, 2010). Por lo tanto Tiahuanaco desempeñó un papel importante en los departamentos costeros de Arequipa, Moquegua y Tacna, en los que se situaban estas encomiendas y donde existieron colonias altiplánicas desde aquella época - a partir de 500 d.C. - , que siguieron conformando pequeños grupos durante el Período Intermedio Tardío y la época inca, y perduraron hasta el siglo XVI (Owen y Goldstein 2002:180).

Entonces para el surandino es importante señalar que el enfoque toponímico valida mucho de esta lengua: los elementos-paya $\sim$-baya $\sim$-waya y-raque $\sim$ laque constituyen evidencias de su presencia. Además, su apariencia en época de los incas según Cerron-Palomino se debe "(a)la estructura genitiva, como en $<$ yndi-n yoca $>$. Compárese este esquema con el de nombres importantes como $<$ Poque-n puquio $>$, $<$ Poque- n cancha $>$, $<$ Oma-n amaru $>$, $<$ Titi-n-huaya- ni $>$, $<$ Vilca-n ota $>$, $<$ Chipi-n-iqui $>$ etc. ; (b) nombres de los incas: $<$ Manco $>$, $<$ Tocay $>$, $<$ Pinahua $>$, $<$ Roca $>$, $<$ Yamque $>$; cf. el híbrido $<$ Yupanqui $>$; (c)nombres de los dioses : $<$ Contiti $>$, $<$ Coa $>$; (d) nombres honoríficos : $<$ Yqui $>$, $<$ Capac $>$ ; (e) nombres de instituciones incaicas : raymi $>$, <quiz>, $<$ kachi $>$, etc". (Cerron-Palomino, s.f.). Además, señala que,

"Tratándose de una lengua extinguida por lo menos desde la segunda mitad del siglo XIX, sin mayor registro documental propiamente lingüístico, no es posible, como en los casos del quechua y del aimara, invocar criterios de geografía dialectal que permitan postular su posible emplazamiento inicial. Sin embargo, gracias a la información documental colonial de los siglos XVI y XVII, .......el archipiélago idiomático puquina que se infiere de los documentos coloniales, jaloneado además por una toponimia persistente, puede sostenerse que la lengua se emplazaba inicialmente en la cuenca del lago Titicaca —el renombrado «lago de Poquina» del que nos habla Guaman Poma-, cubriendo toda la meseta del altiplano y rebasándolo, por la vertiente occidental de los Andes, desde las cabeceras del río Colca (Arequipa) hasta Arica e Iquique, y por la vertiente oriental de los Andes, desde el noreste del lago, y siguiendo por la cordillera oriental de los Andes, hasta cubrir el antiguo territorio del Charcas colonial (Sucre y Potosí).. De otro lado, el descarte mencionado conlleva también una rectificación de carácter designativo, además de reivindicativo. En 
efecto, el examen de la documentación colonial apoyado por la evidencia lingüística, impone un deslinde étnico y glotonímico en el sentido de que por colla, así como por puquina, deben comprenderse, por lo menos inicialmente, a pueblos de habla puquina y no de lengua aimara. Desde la perspectiva de su cultura material, de otro lado, su asociación con la civilización tiahuanacota, y quizás aún con la de los antecedentes de esta, es decir de Pucará y Chiripa ......el puquina habría llegado hasta la frontera natural de La Raya (Sicuani), y, por el este, hasta la región del Colca (Arequipa), entrando en contacto, por consiguiente, con el aimara, que ocupaba los territorios al norte de la frontera delineada (Cerrón-Palomino, 2010, pág. 258)

Adelaar en el análisis sobre "Lenguas y pueblos altiplánicos en torno al siglo XVI" de Alfredo Torero,

"En el caso puquina, no resulta difícil identificar nombres de lugares pertenecientes a esta lengua terminaciones características como baya, -huaya- o paya- laque y -coa revelan la existencia en el pasado de grupos étnicos de habla puquina. La región que con más certeza exhibe características puquinas es el que se extiende desde la ciudad de Arequipa hacia el sudeste y que comprende la mayor parte del departamento de Moquegua y una parte de Tacna, allí se encuentran también los pueblos de Carumas Ilabaya y Locumba identificados por Torero como puquina hablantes en el siglo XVIII. Si en el caso del mismo Arequipa y sus alrededores encontramos toponimia Aymara Umacollo, Chachani, Aniccarahui, Socosani, y la ciudad (Arequipa) hacia el sudeste predominan los topónimos Puquinas como Polobaya, Tiabaya, y Socabaya. También en la zona quechua hablante que ocupa el noreste de las provincias de Arequipa se encuentran algunos pueblos de nombre puquina (Chocalaque, Mollebaya) .... pesar de marcadas diferencias en las costumbres que separan las zonas quechua y aymara en el departamento de Moquegua, se trata probablemente de una región que en su origen fue homogéneamente Puquina. Esta región probablemente fue quechuizada y aymarizada durante la época de la colonia” (Adelaar, 1987)

Jiménez de la Espada en Relaciones geográficas de las indias indica que "el repartimiento de los herederos de Lucas Martínez Begazo es jurisdicción de la ciudad de Arequipa y tendrá como 2000 indios aymaras y más de 1000 indios uros pescadores en el dicho distrito", indica Paul Rivet citando a Lorenzo Machuca,

"es necesario fijarse en el mapa que hemos esbozado del antiguo territorio ocupado por los uros para ver que se ofrecieron a estos hijos de las aguas vías naturales y fáciles para descender desde las altas planicies andinas a los valles y bajas llanuras de costa. Los uros que moraban en las comarcas del lago Titicaca llegaron fácilmente a la región de Arequipa por la cuenca del rio Vítor o Chili o por la vía que sigue el tren de Puno a Mollendo, o por las vertientes del rio Tambo, Los que vivían en las regiones del lago Coipasa ganaron la costa de Pisagua por la quebrada de Camiña y los vecinos de la provincia de lipes llegaron al puerto de Cobija por el rio Loa" (Rivet 219 citado por Bernedo)

Agrega que:

Las primeras poblaciones que se fundó esta ola migratoria hacia sus marchas a la costa fueron los de Ychuña y de Ubinas, en las primeras estribaciones de la cordillera volcánica Y por los desfiladeros norte y sur del Pichu pichu...penetraron en Chiguata, Pocsi Quequeña y Puquina...formaron pueblos como Chiguata, Piaca, Uzuña, Polobaya, Churajon, Chilata, Sechii y Puquina siguiendo el curso del rio tambo. Otra a corriente migratoria penetro por la cuenca del rio Chili entre el Chachani y el Misti vía que actualmente comunica Arequipa con la provincia de caylloma y algunos pueblos de puno. Estos Uros invasores tomaron posesión de la extensa llanura arequipeña formando pueblos de Characato, Paucarpata, Sabandia, Yarabamba, Sogay y Socabaya tomaron Arequipa en su huida de los collas.... Posiblemente fueron los que grabaron los petroglifos que existen en Uzuña y en el alto de la Caldera a ocho leguas al norte de Arequipa" (pag 55)

Siendo estos puquina tiahuanacos, fueron los primeros pobladores de la cuenca del Chili como migrantes, porque antes de ellos existían otros grupos que Galdos denominan "naciones oriundas" sobre este tenor tendrá la arqueología determinar es el caso de Yarabayas, Copoatas y Arunis; luego llegaron los Aymaras, quechuas y finalmente españoles. El descubrimiento de tres cruces cerca de Tingo demuestra que Alata, Sachaca y Tingo fueron poblaciones puquinas.

Un dato interesante fue la anotación del Indio Huaranca "pueblos que existían, antiguos Puluguayas. El Churajón Llamado la Huaca por los españoles. El Puluguaya que esta frente a este pueblo. El Uactalacta cerca de Pocsi, Todos estos pueblos fueron gobernados por el gran cacique de Churajon. El ultimo cacique de este pueblo fue Sacrun el cual fue vencido por los indios venidos del Titicaca, la pelea tuvo lugar en Nawan, hoy Ozuña. Después el imperio quedo en ruinas. Polobaya marzo 1861, Juan Huaranca" (Bernedo, 1949, pág. 61)

Aquí debemos ubicarnos respecto de Bernedo. 1.- los uros no fueron puquinas, sino otro grupo étnico situados en la rivera del lago Titicaca, pero su presencia en Arequipa de uros y puquinas indistintamente se dio. 2.- Los collas no fueron Aymaras sino puquinas Tiahuanaco, es un error de pronunciación con la llegada de los españoles básicamente es Taipicala (puquina) 3.- los aymaras llegan de Ayacucho (Wari) a esta zona; igual que los quechuas que suben desde Huarochiri y Chincha.

Es evidente que un conjunto Aymara altiplánico se enfrenta a estos puquinas es decir no se puede asumir que los collas siempre fueron aymaras, antiguamente fueron puquinas y a medida que se ensanchaban la lengua aymara se hace más utilizable marginando al puquina como se ha visto anteriormente, entonces es probable que los aymara "Collas" en época posterior enfrenten a estos puquinas los cuales migran hacia el Omasuyu, Y otro grupo hacia la vertiente occidental; los de Coipasa se van hacia Cobija y por el rio Loa; los altiplánicos se vinieron por el rio Tambo; y otro grupo se vino por la cuenca del Chili y justamente comparten lo que la arqueología denomina la expansión Tiahuanaco y es ratificada con los dominios puquinas tanto en el altiplano como en la costa del pacífico en la cuenca del Loa, Tambo y Chili.

"El hecho que la lengua puquina coincida con la ocupación territorial Tiahuanaco constituye una prueba contundente de que dicha sociedad y dicho idioma fueron los protagonistas de esa era (600dc-1200d.c) por lo que la correcta terminología debe ser Civilización puquina y no cultura Tiahuanaco" (Lumbreras, 2005, pág. 139)

El contexto Tiahuanaco como vimos en la arqueología de 
la Chimba y Tiabaya resulta fundamental para comprender la presencia del puquina en esta zona.

Las fuentes de la cultura puquina en Arequipa son las actas del sínodo reunido bajo la dirección de don Pedro Villagómez en 1638 donde se consideró la necesidad de redactar un catecismo ya que en algunas doctrinas del obispado se habla el puquina, además existe un documento en 1813 en él se manifiesta que en la provincia de Condesuyos obispado se Arequipa se hablan seis idiomas: quechua, Aymara, Colic, Puquina, Isapi, Chinchaysuyo (Almonte 1813: 8)

Se ha determinado respecto de la documentación que existe sobre el quechua y el aymara una ausencia de traducciones en catecismo o diccionarios de la lengua Puquina a pesar de ser considerado Lengua General por Toledo según Lumbreras es por un documento de 1573

Habiendo visto con las lenguas que yo trataba y la de los sacerdotes y religiosos que en la mayor parte del Collao y provincia de Chucuito hablaban una lengua que llamaban aymara que es más oscura que las demás, los hombres. Y que las mujeres hablaban otra que llamaban puquina tan cerrado que ningún sacerdote practico y cursado que sea en las lenguas las habla ni entiende, a causa ni ellos pueden cumplir con la obligación que tiene de predicarlos ni enseñarlos, ni vuestra Magestad descargar su real conciencia (AGI)

Refutado por Bouysse ya que el puquina estaba en decadencia y no era solo de uso de mujeres o lengua familiar, lo que se dio es un proceso de discriminación debido a la imposición del aymara por ser lengua común y se masificó incluso en los grupos puquina, ya que era de uso cotidiano en el comercio, sociedad y política; relegando paulatinamente al puquina.

Se impone la comprensión de topónimos, onomástica pero sobretodo en las costumbre, las cultura; el hecho que tengan contactos con otras lenguas y saberes hacen que se dé una prelación en el tiempo de estas, pero sobre todo la capacidad de convivir en zonas quechuas con el puquina y viceversa además del aymara donde hay quechua y puquinas; ante tal abigarramiento de colores culturas y lenguas es muy sutil las líneas lingüísticas y es de esa forma como debe entenderse, evitar encasillar en estructuras de unilaterales que no permiten la comprensión de ese mundo que hoy día es nuestro mayor legado.

\section{Lingüística y toponimia puquina}

Hay dos categoría etimológicas 1) las estrictamente lingüísticas, cuya traducción se hace forma literal de acuerdo a lo que arrojan el análisis de sus raíces. 2) las antropológicas, que explican la función que desempeñaban en el contexto económico, social, político y de grupo (Lumbreras, 2005, pág. 129)

De acuerdo a Bernedo Málaga existen expresiones lingüísticos y topónimos característicos, para ello se basa en el "rituale Seu Manuale Peruanum" de Gerónimo de Ore, lo que no queda claro si este catecismo fue elaborado por Barzana en el siglo XVII, ya que hay indicios que el original se perdió y que según algunos investigadores, la traducción de Oré tiene muchas inexactitudes y está altamente quechuizado.
Pasemos a ver el padre nuestro en Lengua Puquina "señiki, hanigo pacas cunnana ascheno

Pomana upalli suhanta po capaca

Asheno señ guta kiguri hanigo pa casna

Ehe cahu cohuacasna hamp

Kaa gamenke ehe hesuna:

Señ guta camen tanta, señ

Hochahe pampache surnao keno gata

Pampachanganch cagu: Ama ehe

Acro suma huchaguta señ hotonnava

Enhata entonana suman"

Frases en lengua puquina

$\begin{array}{cc}\text { Dame pan } & \text { lulisunnai } \\ \text { Ven aca } & \text { Ascai } \\ \text { Anda Vete } & \text { Tukaca ocsai } \\ \text { Habla conmigo } & \text { Chischai } \\ \text { Te fuiste sin avisarme } & \text { Churacmacuaur } \\ \text { Después de comer } & \text { Luklihua mahuir } \\ \text { Se ha perdido } & \text { Churatan cualayu o churatan hualaur } \\ & \text { (Bernedo, 1949, pág. 82) }\end{array}$

Toponimia y onomástica puquina en Arequipa tenemos

\begin{tabular}{|c|c|}
\hline Characato & Cerro de cumbres relucientes \\
\hline Pocsi & lugar en forma de plato \\
\hline Piaca & verbo pakari pueblo en formación \\
\hline Quequeña & lugar rocoso, solido \\
\hline Churajon & pueblo sabio \\
\hline Zeki & vientre \\
\hline Chilata & Majada \\
\hline Sogay & Testículos \\
\hline Para-na-i & carbón de leña \\
\hline Kutipa & $\begin{array}{l}\text { color amarillo, apellidos delas familias } \\
\text { de Chapi }\end{array}$ \\
\hline Lipe & carne (apelativo de Uzuña o polobaya) \\
\hline Ocola & $\begin{array}{c}\text { Casa (apelativo de familias de } \\
\text { Quequeña) }\end{array}$ \\
\hline Chi-hui & $\begin{array}{c}\text { Arroz (apelativo de familias de } \\
\text { Quequeña) }\end{array}$ \\
\hline Qui-chi-ni-huay & pueblo en barranco \\
\hline Chocora & culebra, usado en Uzuña y polobaya \\
\hline Malakai & Tia (voz corriente en chilata y Piaca) \\
\hline Ana-Chuchuni & feo, usado en Pocsi \\
\hline Kaliño & Pescado \\
\hline Ua-ka-le & Corazón \\
\hline Kibero & plato de barro, se usa en Tuctumpaya \\
\hline Zuruque & maíz triturado \\
\hline Siruma & la nube \\
\hline Yuquila & lugar salitroso \\
\hline Na-wan & Joven, lugar cerca de Uzuña \\
\hline Cora-ua-ya & agua que canta, lugar cerca de Uzuña \\
\hline Tu-rata & Brillante (Uzuña) \\
\hline Tuana & Mujer, (Uzuña) \\
\hline Hui-hui & vertiente pequeña, usado en Piaca \\
\hline
\end{tabular}


Kamanchaca, niebla, usado en Pocsi y Quequeña y generalizado en la costa y lomas del Sur. Como inquiere Bernedo son los vocablos que en la actualidad aún se mantienen en la vida cotidiana y toponimia de la zona es necesario aclarar que pertenecen a este espacio ya que el autor estando en la parroquia de Quequeña tuvo la posibilidad de recorrer esta zona, lo cual no inhibe que en otras áreas puquinas se encuentren onomástica y toponimia diferente, lamentablemente Eloy linares Málaga en sus "centros Arqueológicos con étimos Quechuas, Aymaras y puquinas" no hace la clasificación por lengua o dialecto, la cual finalmente no permite elucidar las raíces y sufijos en la comprensión de la construcción de este texto, ya que denota insuficiente la evidencia arqueológica para un tratamiento etimológico puquina

\section{¿El puquina en la Chimba y Tiabaya?}

Es necesario entender que muchos de los topónimos hoy, han sufrido variaciones tanto en su significado y forma, como hemos señalado líneas arriba la región sur occidental de la cordillera volcánica a partir de los estudios arqueológicos e etnohistóricos se considera que hubo presencia puquina por la cuenca del Chili pero que a su vez también lo ocupo Aymaras quechuas y finalmente españoles, entonces esta demás decir que existe un topónimo cuyo significado sea el definitivo, teniendo que asumir incluso nombres prestados por los españoles es el caso de muchas zonas geográficas incluso Perú que deviene de Piru que para los oídos de los españoles era la que definía este territorio, lo cual en términos prehispánicos no existía, sino más bien tawantinsuyo, como demostró Pease asumiendo que era una construcción lingüística recuperada 40 años después de la conquista, pero lo fundamental como Bloch señalara en una libro básico de historia no está tanto en sacralizar el origen, sino lo que significo en los tiempos que le toco concebirse al vocablo.

Entonces creemos que existen dos perspectivas para poder definir Tiabaya: como préstamo hecho por los españoles a pesar que la mención de esta palabra se encuentra en la visita general del virrey Toledo y de otra parte comprender que Tiabaya tuvo una acepción Puquina, Aymara, Quechua además del entendimiento castellano de este vocablo; pero existe una acción fundamental en el hombre, tratar de conocer su percepción del ayer desde y percepción del mundo que le rodea hoy; entonces también sufren de interpretaciones a veces antojadizas al respecto.

Es necesario aclarar que en la fuente etnohistórica -Vista de virrey Toledo- la escritura que se tiene de esta ciudad es Tiyavaya probablemente lo que entendieron los visitadores tanto civiles como eclesiásticos del siglo XVI y XVII. Veamos sus diversos significados a la luz de los procesos.

En Aymara, el estudio "Aymara compendio de estructura fonológica y gramatical” de Martha Hardman, Juana Vasquez, Juan de Dios Yapita y otros" (2001, pág. 109)

Menciona que Waya es Distancia de las personas o ubicación personal, Y Tia, Agua; cuyo significado seria cerca de las aguas.

Tiya es hacer y wayanka es Bolsa

El prefijo Ti según fray Baltazar de Salas es estaño, Ti también puede ser cansancio; Tia, según Theodore Bess es Ribera

En quechua Tiyay, haber, tener, y para el sufijo vaya no existe una traducción, para Waya o Wayaqa es talega,

Es evidente que estas traducciones están enfatizadas en la formación morfológica y semántica de la palabra por lo que es necesario recurrir al toponimia y onomástica, según Eloy Linares Málaga en Centros arqueológicos con Étimos, quechuas aymaras y puquinas (1982, pág. 7)Tio es se refiere a la jurisdicción de Tiabaya Ttio "se refiere a arena suelta, sentarse ¿Arboleda?"

Contamos con el aporte de Samuel Mamani Ilaquita, ${ }^{2}$ quien nos informó a partir de los estudios de Zarate Santillana, Falconi Picardo, Espinoza Galarza y el Dr. Galdos,

"TIABAYAY : Que significa: persona sentada en espera de alguien (antesala). También podría provenir de :TIAPAYANA : Que significa : lugar de descanso; según el curso de quechua del profesor Hernán Huarache M. Otros afirman que el nombre de Tiabaya vendría del verbo quechua y/o aymara:
TIAY - PAYA
Siéntate vieja
TIA - WAYA
Arena Suelta

Para entender lo que significan las voces TIA y BAYA, nos permitimos buscar en las indagaciones realizada en el sector, de lo que hoy, es el distrito de Socabaya, por la similitud y los aspectos comunes que tiene con Tiabaya. En ese sentido nos remitimos al trabajo realizado por el Dr. José Falconi Picardo (2000) citando a Lic. Juan domingo Zamácola y Jauregui afirmó que derivaría del SUCCAYA que quiere decir campo de los sepulcros versión que a él le dieron sujetos "versados en la lengua general de las Indias". Según el Dr. Justo Ruelas Quispe, es "una mezcla de aymara y quechua" afirmando que sería SOKKA WAYA que quiere decir región o lugar donde hay arena suelta, cosa algo similar dice el Dr Eloy Linares Málaga, quien, viene de la palabra quechua SOKKA - AYA que significa camellones de tierra aflojada, para otros Socabaya viene del SOCCA - PAYA que quiere decir vieja canosa. Sin el ánimo de entrar en discusiones (continua describiendo, Falconi Picardo (2000) y considerando que en la región existían habitantes antes que los collas y quechuas, estamos de acuerdo con el Dr. Guillermo Galdos, que el vocablo o sufijo BAYA es de influencia idiomática PUQUINA, observándose que hoy muchos lugares geográficos del sector que terminan en HUAYA, GUAYA, WAYA o ( BAYA según la pronunciación en español)......en Tiabaya y Socabaya vivían desde tiempo inmemorables moradores llacta-runas $\mathrm{u}$ oriundos. La estructura social y política pre-inca e inca no estaba concebida en ciudades o centro poblados, en estos dos sectores, en consecuencia no habían ciudades, a excepción

${ }^{2}$ Servidor público de la Municipalidad de Tiabaya, Articulo monográfico del Ps. SAMUEL MAMANI YLAQUITA, Mayo, 2010 
de la ciudad Churajon de Yumina. El Dr. Guillermo Galdos, nos dice con relación a la población indígena que había en Arequipa: Los Yarabayas ocupaban desde casi la lloclla de san Lázaro, hasta Tingo $($ Tinku $=$ encuentro del rio Chili y el rio Socabaya) y cerca de Huasacache.”. También se tiene evidencia de que otro grupo de Puquinas habitaron el valle de Tiabaya y Congata (Quncata), en las márgenes izquierda y derecha de esta sector. En el sector de Tiabaya entonces hubo influencia puquina- Churajon, según lo evidencia el toponimo Tia - waya., Arancota. Así mismo influencia aymara, por los toponimos, Alata, markarani e influencia quechua, por sus toponimos; Chusicani, el O’cco, Phatasahua, katari, Puquio, chinccana, Qunkata, Anansaya (parte alta del sector de Tiabaya) y Urinsaya (parte baja de Tiabaya). Remarcamos que a la fecha no se han encontrado los argumentos suficientes para conocer el verdadero significado de la palabra Tiabaya. Resultando fuera de lugar el pretender descifrar en el idioma quechua o aymara, dado que no tiene sentido nombrar toponímicamente a este hermoso lugar con términos de : "Vieja sentada" o "siéntate vieja". Tal vez, se pueda deducir de los apuntes anteriores, el término "arena suelta", por las características topográficas en el que se asienta actualmente el pueblo de Tiabaya...... WAYA es un sufijo usado en el Puquina que significa región, extensión, sector. Mientras que la voz TIA, aún no se puede descifrar en su significado original, en el idioma Puquina.

En versión oral nos trasmitió que Tiabaya de acuerdo a la toponimia es valle de las riberas, que es lo que se observaría desde el cerro Huayrondo, nótese además que Tiabaya está cruzado por dos ríos el Socabaya y el Chili los cuales se encuentran aguas arriba en la confluencia de Huayrondo, asimismo existe una acequia antigua que se desprende del Chili para irrigar esta área feraz .

Desde la perspectiva puquina en los estudios de Cerrón Palomino, este topónimo significaría

Titi--------------------sol

Baya, Paya, Huaya -----llanura, pampa

Entonces tenemos pampa asoleada, llanura templada; y ¿porque esgrimimos esta propuesta?, Arequipa propiamente se encuentra en una altura diferente la cual el microclima es más frio; en cambio Tiabaya a diferencia de las poblaciones valle arriba tiene un microclima agradable durante todo el año. Necesitamos más información lingüística, etnohistórica y sobre todo la comprensión de la naturaleza y los hombres para acercarnos definitivamente al significado de este topónimo, pero nuevamente se recalca que el vocablo ha pasado por un proceso de un puquina antiguo, ser comprendido desde el marco no digo solo la morfología, sintaxis y gramática Aymara, sino toda la fuerza de la percepción del mundo que tuvo esta cultura, de igual forma el Quechua hasta su castellanización y lo que el poblador cree y percibe en su significado, debemos entender que la trama de la vida esta signada por la valoración que da el ser humano de su entorno y probablemente sea los más cercano a su conocimiento; como Ricoeur asistía hace algunas décadas cuando ideó que las significaciones históricas eran válidas no solo por el hecho o proceso histórico en que se dió sino en el verdadero sentido que hace el lector de un libro de historia, termina no tanto importando lo que el hecho histórico significo ni lo que el investigador expuso, sino lo que entiende su acucioso leedor es decir termina apropiándose de la idea, finalmente es lo que queda, entonces tiabayas como fueran: puquinas, quechuas, aymaras o españoles, lo cierto es que existen con una grandeza cuyo historia está construida por ellos más allá de la sabia elucubración de la buena teoría.

\section{REFERENCIAS BIBLIOGRÁFICAS}

1. Adelaar, W. (1987). Comentario a "lenguas y pueblos altiplánicos en torno al siglo XVI. Revista Andina año 5 nro 2 Cusco P. 373, 373.

2. Arkush, E. ( 2012). Los Pukaras y la Poder: Los Collas en la Cuenca Septentrional del Titicaca. En L. F. Blanco, Arqueología de la Cuenca del Titicaca, Perú (págs. 295-320). Lima : IFEA.

3. Barriga. (1941). Memorias para la historia de Arequipa , la visita del intedente Alvarez y Jimenez. Arequipa: Colmena, tomo I.

4. Bernedo, L. (1949). La cultura Puquina. Lima: Ministerio de educación pública.

5. Bouysse-Cassagne, T. ( 2010). Apuntes para la historia de los puquinahablantes. BOLETÍN DE ARQUEOLOGÍA PUCP / N. ${ }^{\circ} 14$ / ISSN 1029-2004, 283-307.

6. Cerron-Palomino. (s.f.). Las lenguas de los incas. Lima: PUCP.

7. Cerrón-Palomino, R. (2010). Contactos y desplazamientos lingüísticos en los Andes Contactos y desplazamientos lingüísticos en los Andes. BOLETÍN DE ARQUEOLOGÍA PUCP / N. ${ }^{\circ} 14$ / 255-282 / ISSN 1029-2004, 255-282.

8. Lumbreras, L. (2005). Las lenguas nativas del altiplano peruano boliviano en el siglo XVI. Historia año IX N 14, Lima, 121-153.

9. Malaga, E. L. (1982). Centros arqueológicos con Etimos, quechuas aymaras y puquinas. Arequipa: Dirección universitaria de Investigación UNSA.

10. Martha Hardman, J. V. (2001). “Aymara compendio de estructura fonológica y gramatical”. La Paz: ILCA. 